\title{
Imaging evaluation of renal masses
}

\author{
Mohi J.K. ${ }^{1}$, Kajal S. ${ }^{2}$, Singh J. ${ }^{3}$ \\ ${ }^{1}$ Dr. Jaswinder Kaur Mohi Associate Professor Radiodiagnosis GMC Patiala, ${ }^{2}$ Dr. Sunita Kajal Consultant \\ Radiologist SGHC Hospital Sohana, ${ }^{3}$ Dr. Jasvir Singh Junior Resident, Radiodiagnosis, GMC Patiala, Punjab, \\ India
}

Address for Correspondence: Dr. Jasvir Singh Junior Resident Radiodiagnosis GMC Patiala E-mail: jasvirsingh011789@gmail.com

\begin{abstract}
Introduction: This article demonstrate the imaging characteristics of cystic and solid renal masses, along with a summary of identified imaging criteria that may be of use to differentiate masses that are more likely to be benign from those that are more likely to be malignant. Aim and Objectives: To evaluate the patients with renal cancer by ultrasonography (USG) and computed tomography (CT) and to compare the findings of USG and CT. Material and Methods: Present study was conducted on 60 patients presented with renal masses, initially evaluated with ultrasonography (USG) and later on characterization of the mass was done by using computed tomography (CT). Results: CT has higher sensitivity, specificity, accuracy, positive predictive value and negative predictive value for renal cell carcinoma (RCC) on correlation with USG. Conclusion: CT is capable of detecting tumor invasion of perinephric fat and adjacent muscles, which cannot usually seen by ultrasound. While both CT and ultrasound demonstrate venous and retroperitoneal tumor extension, CT is more reliable.
\end{abstract}

Key words: Renal mass, RCC, USG, CT scan.

\section{Introduction}

Renal cell carcinoma is the most common primary malignancy of kidney accounting for $2 \%$ of all cancer diagnoses [1]. RCC is the most common tumor to involve the kidneys and accounts for 80$90 \%$ of primary malignant renal neoplasms in adults [2]. Usual clinical presentation of malignant renal neoplasm is in the form of hematuria, flank pain or lump abdomen

Imaging retains a key role in diagnosing, staging, and follow-up of RCC. Plain abdominal radiograph (KUB) and intravenous urography (IVU) may hardly ever the initial study to depict a renal mass. Each modality has advantages and drawbacks; CT still is the first choice for imaging of renal masses as it is the least complex and most well understood by clinicians. US are the most commonly used technique worldwide owing to its convenience, low cost, and portability, allowing its use in the operating room [3].

Manuscript received: $26^{\text {th }}$ May 2017

Reviewed: $06^{\text {th }}$ June 2017

Author Corrected: $12^{\text {th }}$ June 2017

Accepted for Publication: $19^{\text {th }}$ June 2017
Real-time and color Doppler US represent the most frequently used imaging tools for the initial diagnosis in patients with suspected RCC and offer valuable information on tumor vascularity and major venous vascular involvement. The gold standard for characterization, staging and surveillance of RCC is still the CT and represents powerful tool for preoperative planning in the era of minimally invasive treatments [4]. Our hypothesis was to evaluate the patients with renal cancer by ultrasonography (USG) and computed tomography (CT) and to compare the findings of USG and CT.

\section{Material and Methods}

This was prospective observational study that was carried out for a period of 3 years in Rajindra Hospital Patiala. Permission for conducting the study was obtained from institutional ethical committee. 60 patients were included and presented with clinically suspected renal masses confirmed on USG in both males and females of any age group. Patients presenting with simple cysts on 
USG were excluded from study. Relevant history, clinical examination and routine investigations were done. Patients underwent ultrasonography (USG) Ultrasound machine (Philips Envisor) using and computed tomography (CT scan) CT scanner (Siemens Somatom Emotion 6-slice) investigations.

\section{Ultrasonography Technique- USG was} performed with Philips Envisor machine. An appropriate transducer frequency ranging from 2.5 to $5 \mathrm{MHz}$ was used, depending on the body habits. The sonographic examination of the kidneys included long axis and transverse views, assessment of the cortex and central sinus. Kidneys and perirenal regions were assessed for abnormalities.
CECT Scan Technique- Examination was conducted on Siemens Somatom Emotion, six slice CT machine. Slice thickness of $8 \mathrm{~mm} \times 8 \mathrm{~mm}$ collimation was used. Pre contrast study of the kidneys was performed initially followed by the post contrast study of the kidneys, 70-80 seconds after the initiation of intravenous bolus of contrast injection. Initial post contrast study was performed in the nephrographic phase of renal enhancement. Delayed CT was performed using same parameters as used in initial postcontrast study.

Contrast Material- Nonionic iodine contrast $300 \mathrm{mg}$ was used in our study. $100 \mathrm{ml}$ of contrast was injected intravenously by the peripheral intravenous route at the rate of $2-3 \mathrm{ml} / \mathrm{sec}$. Continuous monitoring of the vital parameters was done during contrast injection.

\section{Results}

This prospective study was carried out in Rajindra Hospital, Patiala. Sixty patients were selected from the OPD and wards of the hospital. Relevant data about patient's name, age, sex, clinical history, physical examination and routine relevant investigations were recorded as per plan. Out of 60 patients included in study 34 were males $(56.66 \%)$ and 26 were females $(43.33 \%)$ with male to female ratio of 1.3:1. Most common age group was 51-60 yrs contributed $21.66 \%$ followed by age group 41-50 yr (20.0\%). Out of 60 patients included in study RCC was found in 29 patients, Wilm's tumour in 3, metastasis in 4, renal lymphoma in 2, angiomyolipoma in 4, abscess in 7 , pyonephritis in 4 , hydatid cyst in 1, renal hematoma in 1, perinephric collection in 1 , oncocytoma in 1, complex cyst in 2 patients and adrenal mass in 1 patient. Out of the 29 patients with RCC, almost $65.5 \%$ were males and $36.7 \%$ were females, giving a male: female ratio of 1.6:1. Maximum patients belong to the age group 61-70 years (31\%) followed by $51-60$ years of age group $(24.13 \%)$.

Table-1: Appearance of RCC on USG and CT

\begin{tabular}{|c|c|c|c|c|}
\hline & No of lesions detected & Solid & Cystic & Solid/cystic \\
\hline USG & 26 & 22 & 2 & 2 \\
\hline CT & 28 & 24 & 1 & 3 \\
\hline
\end{tabular}

of 26 lesions detected by USG, 22 (84\%) masses were solid and 2 masses were cystic and on the other hand out of 28 cases, $24(85 \%)$ masses were solid and 1 was cystic on appearance in CT. Cystic mass was found on USG in one patient but when CT was performed it shows enhancing nodule that was later found to be cystic RCC on FNAC. About 2 lesions show solid and cystic component on both USG and CT.

Table-2: Echo pattern on USG

\begin{tabular}{|c|c|c|c|}
\hline Isoechoic & Hypoechoic & Hyperechoic & Heterogenous \\
\hline $15(57.6 \%)$ & $02(7.6 \%)$ & $02(7.6 \%)$ & $07(26.9 \%)$ \\
\hline
\end{tabular}

Table-3: Appearance on CT

\begin{tabular}{|c|c|}
\hline Heterogenous & Cystic \\
\hline $27(96.4 \%)$ & $01(3.5 \%)$ \\
\hline
\end{tabular}

Most common echopattern on ultrasound was isoechoic in $57.6 \%$ followed by heterogenous and hypoechoic. $96 \%$ masses were heterogenous followed by cystic lesions on CT (3.5\%). 
Table-4: Size wise distribution of RCC Lesions

\begin{tabular}{|c|c|c|}
\hline Size & USG & CT \\
\hline Less than $3 \mathrm{~cm}$ & 01 & 02 \\
\hline $3-7 \mathrm{~cm}$ & 10 & 11 \\
\hline More than $7 \mathrm{~cm}$ & 15 & 15 \\
\hline
\end{tabular}

1 lesion was less than $3 \mathrm{~cm}$ on USG and CT. 1 lesion was missed on USG that was detected on CT which measuring less than $3 \mathrm{~cm}(2.6 \mathrm{~cm})$ in size.

Table-5: BOSNAIK Classification of cystic lesions

\begin{tabular}{|c|c|c|}
\hline & Cystic lesion & Solid and cystic lesion \\
\hline USG & 2 & 2 \\
\hline CT & 1(Bosnaik type 2) & 3 (Bosnaik type 3/4) \\
\hline
\end{tabular}

Two lesions were detected as cystic masses on USG, one of these shows internal echoes on USG and was found to be cystic mass with enhancing septae on CT (Bosnaik type 2). Enhancing nodules were seen on CT in second cystic lesion (Bosnaik type 3/4) detected by USG. Other two lesions showed both solid and cystic components on both USG and CT (Bosnaik type 3/4). Figure 3 shows mutiloculated multisepaed cystic mass with enhancing wall and solid component in right kidney (BOSNIAK 4).

Table-6: imaging characteristics of RCC found on USG and CT

\begin{tabular}{|c|c|c|}
\hline Imaging features & Ultrasound & CT \\
\hline Calcification & 06 & 06 \\
\hline Collaterals & 00 & 01 \\
\hline Fat component & 00 & 15 \\
\hline Perinephric extension & 00 & 02 \\
\hline IVC Thrombus & 02 & 02 \\
\hline Increased diameter of inferior vena cava (IVC) & 02 & 17 \\
\hline Lymphadenopathy (LAP) & 11 & 0 \\
\hline
\end{tabular}

Calcification was seen in 13 cases on CT and in 6 cases on USG (Figure 2 USG and CT demonstrate a heterogenous mass with calcification). LAP was seen in 17 cases on CT and in 11 cases on USG. IVC thrombus was seen in 2 cases on USG and CT which was shown in figure 1. CT additionally detected perinephric extension in 15 cases, collaterals in 6 cases and fat component in one lesion.

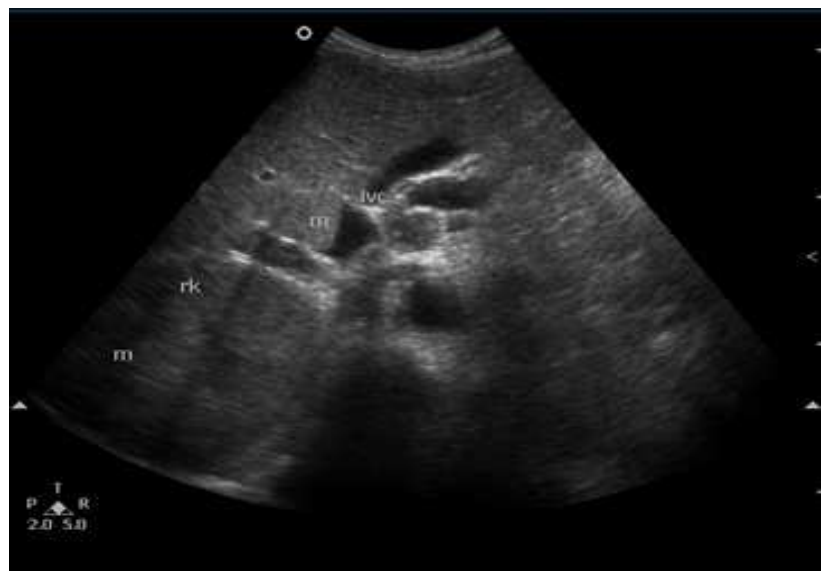

Figure-1A: Ultrasound image showing heterogenous well-defined mass in upper and mid pole of right kidney. IVC is dilated and shows an echogenic material consistent with thrombus. 
Original Research Article

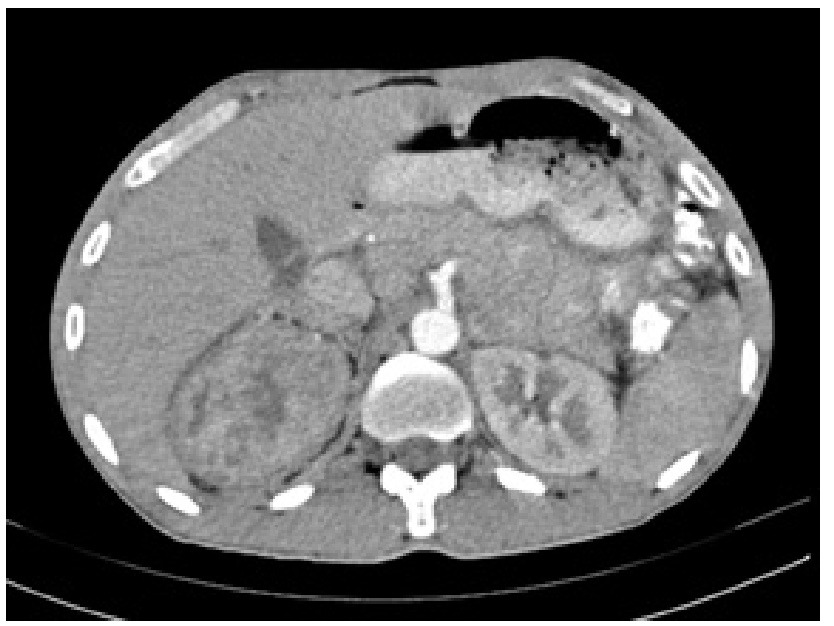

Figure-1B: Computed tomography image showing a heterogeneously enhancing mass is seen in upper and mid pole regions of right kidney. Lumen of IVC is expanded and shows heterogenously enhancing mass suggestive of tumour thrombus.

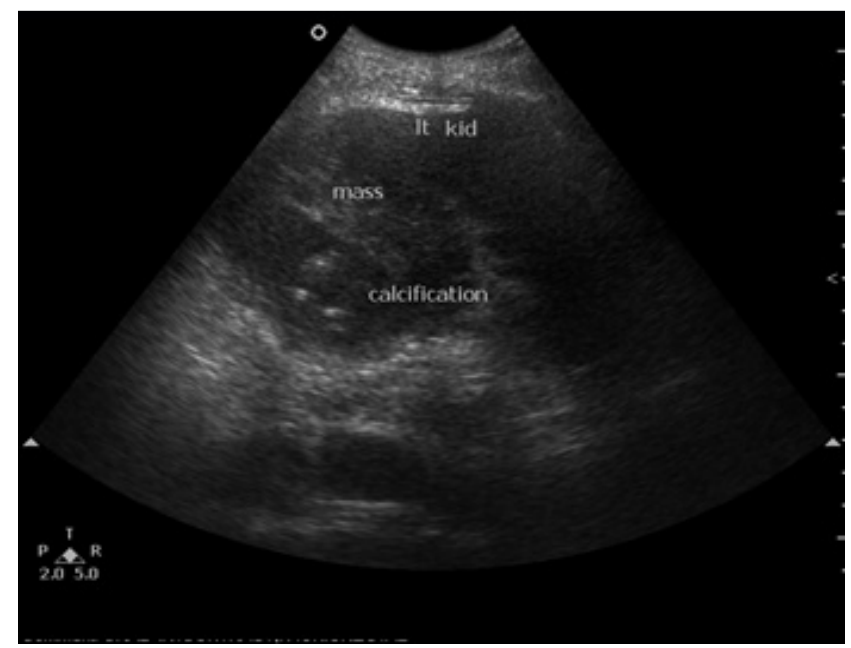

Figure-2A: Ultrasound image showing a heterogenous mass with multiple foci of calcification is seen in upper and mid pole of left kidney.
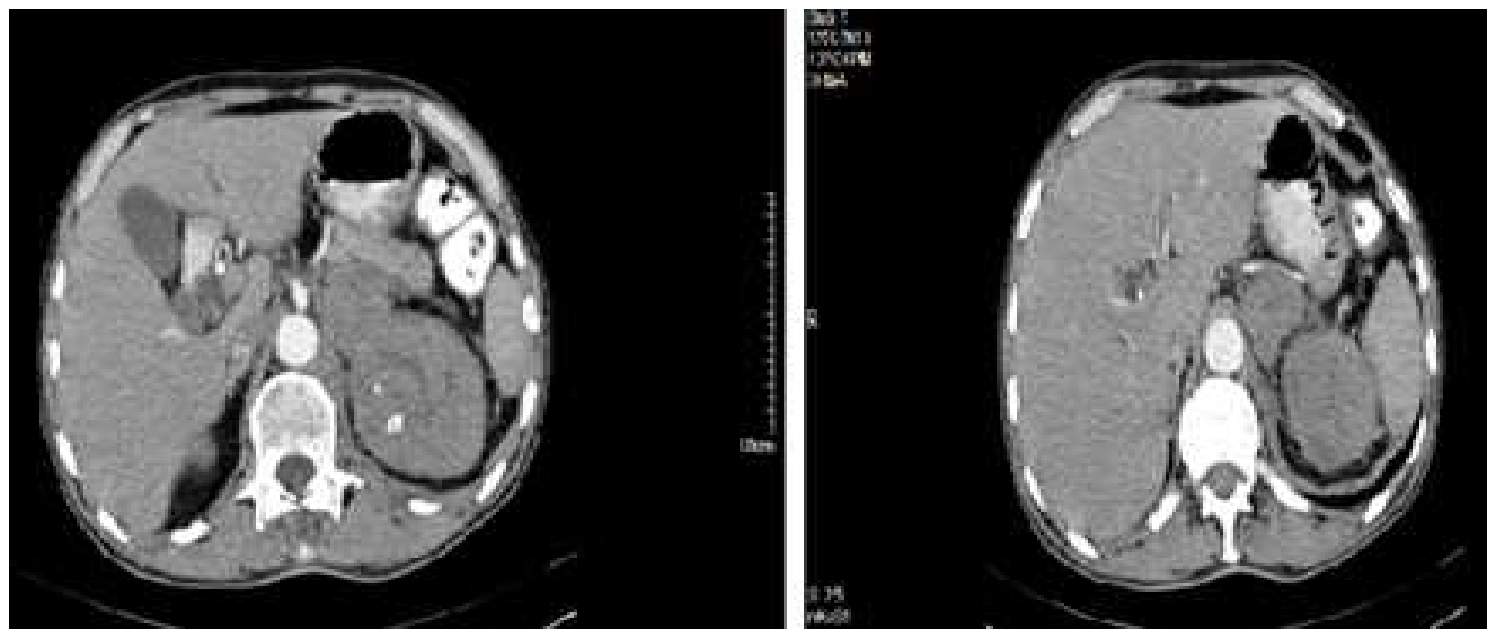

Figure-2B: Computed tomography image showing a heterogeneously enhancing mass with calcified foci and necrotic areas is seen involving upper and mid pole of left kidney. Another poorly enhancing mass is seen in left adrenal gland suggestive of adrenal metastasis. 


\section{Original Research Article}
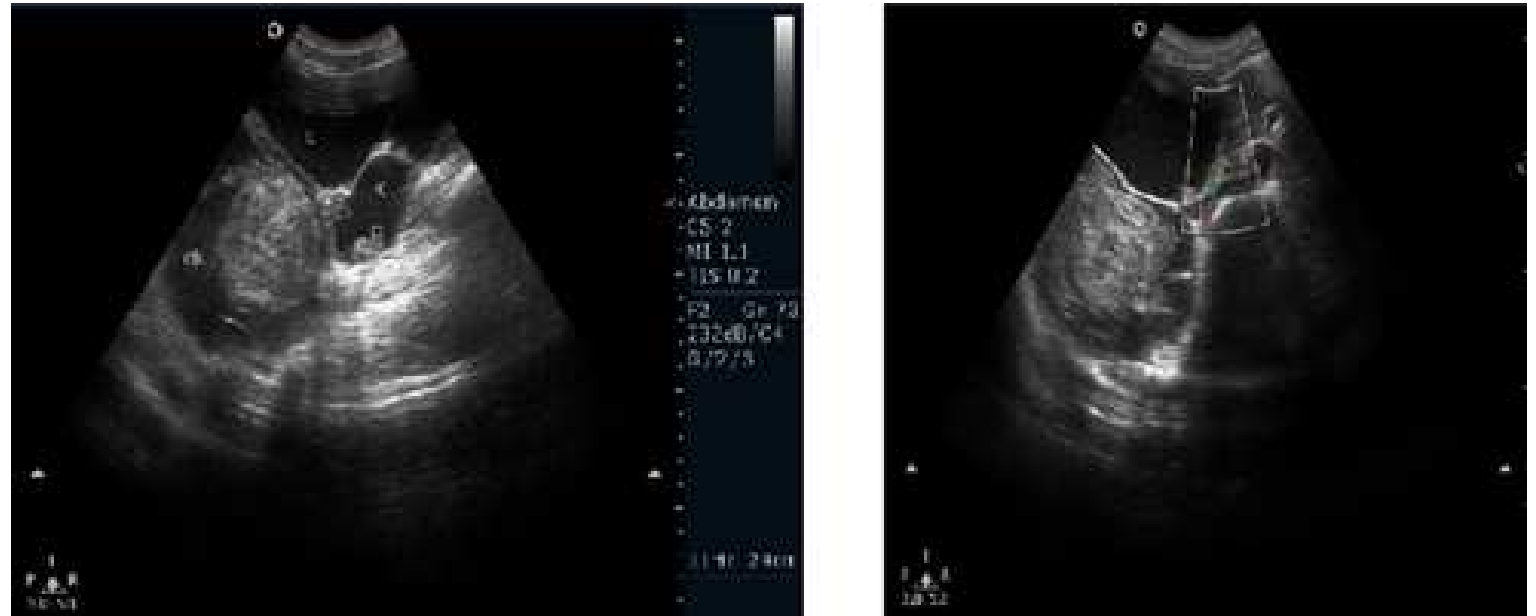

Figure-3A: Ultrasound image showing a multiloculated, multiseptated cystic mass with solid component in right kidney. Septations and solid component show vascularity on colour Doppler.
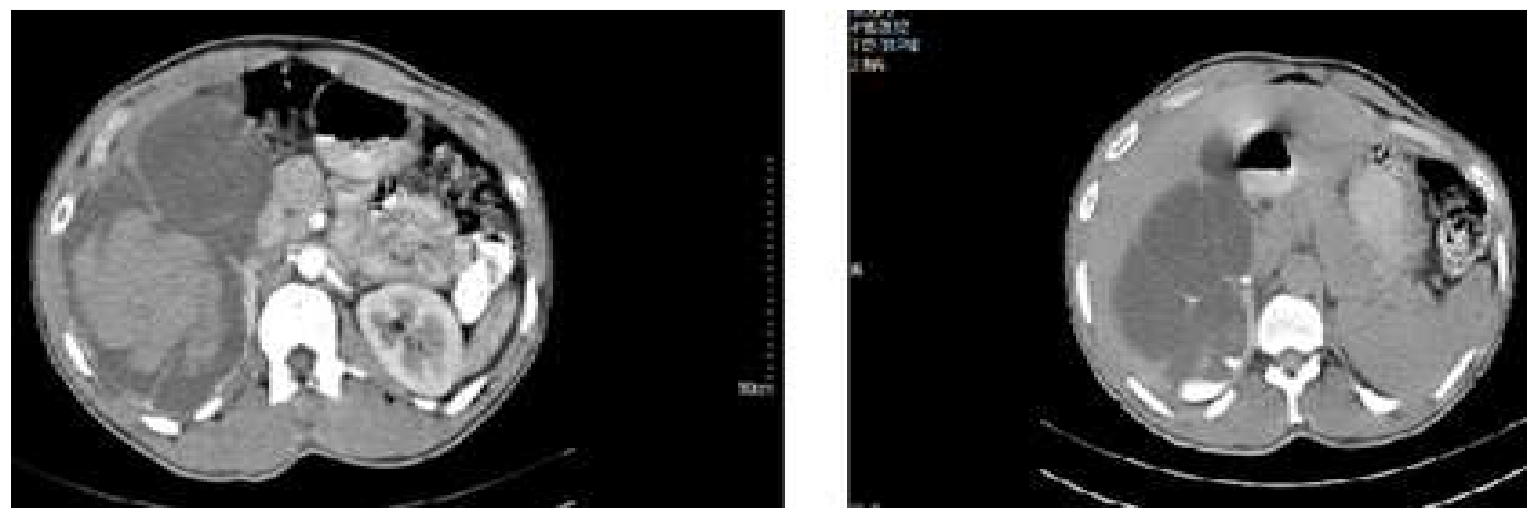

Figure- 3B: Computed tomography image showing a multiloculated, multiseptated cystic mass with enhancing septations, walls and solid component in right kidney. (BOSNIAK 4)

\section{Discussion}

RCC was most commonly found renal lesions constitute 29 (48.33\%) of total renal lesions followed by angiomyolipoma/metastasis $4(6.66 \%)$ and Wilm's tumour 3(5\%). Neoplastic lesions constitute $71.6 \%$ and inflammatory lesions constitute $23.3 \%$ of total lesions. Our study correlates with study of Bajwa et al [5] (2007) in which renal cell carcinoma was the commonest found renal lesion (45.8\%) followed by Wilm's tumour (4.28\%), transitional cell carcinoma (2.8\%), lymphoma and angiomyolipoma (AML) in 1.4\% each. Neoplastic lesions were observed in $39(55.7 \%)$ cases and inflammatory lesions in 23 cases $(32.9 \%)$ in their study.

RCC was also commonly detected and evaluated renal neoplasm in study of Hatimota et al [6]. Out of 29 patients with RCC, 18 (62\%) were males and 11 (37.9\%) were females, giving a male: female ratio of 1.6:1. Similarly, in studies conducted by Linblad [7] (2004), Lipworth et al [8] (2006) and NG et al [9] (2008) renal cell carcinoma emerged as the commonest tumour in men than in women. Men to women ratios of these studies are shown in Table-7.

Table-7: Male to female ratio in $\mathrm{RCC}$ in various studies

\begin{tabular}{|c|c|c|c|c|}
\hline & Present Study & Linblad [7] (2004) & Lipworth et al [8] (2006) & NG et al [9] S(2008) \\
\hline Ratio & $1.6: 1$ & $2.5: 1$ & $1.5: 1$ & $2: 1$ \\
\hline
\end{tabular}


Maximum patients with RCC belong to the age group 61-70 years (31.0\%) followed by 51-60 years of age group (24.13\%) with mean age of 56.7. Studies conducted by Linblad [7] (2004) Lipworth et al [8] (2006) and NG et al [9] (2008) showed that highest incidence rates of RCC were in the sixth and seventh decades. Hence, the age incidence and male predominance is not an incidental finding in our study.

USG correctly diagnosed 26 cases of RCC as against 28 cases on CT (true positive). 3 cases were false negative and 4 were false positive on USG. 1 case was false negative and 1 was false positive on CT.

\section{Table-8: RCC detection on CT}

In study conducted by Warshauer et al [10] (1988) specificity, positive predictive value and negative predictive value of USG for the detection of renal masses were $91 \%, 82 \%$ and $73 \%$ respectively. Our study correlates with study of Levitt et al [11] which concluded that CT and USG offer complementary and supplementary role in the evaluation of renal and pancreatic disease. In their study specificity, sensitivity, positive predictive value and negative predictive value of CT for detection of renal masses were $100 \%, 90 \%, 100 \%$ and $96.88 \%$. Accuracy was $97 \%$ as against $96.6 \%$ in our study. However, sensitivity of USG was $60 \%$ in their study that is low in comparison to our study $(89.66 \%)$. Specificity, positive predictive value, negative predictive value and accuracy were $100 \%, 100 \%, 84 \%$ and $87 \%$ respectively.

Our study correlates with studies of Sagel et al[12], Bajwa et al[5] (2007), King [13] (1972) and Dachille et al[14] (2005) that demonstrated similar values as in present study for the detection of renal masses on USG and CT as shown Table 9 and Table 10.

Table-9: Role of CT in evaluation of RCC in different studies

\begin{tabular}{|c|c|c|c|c|c|}
\hline Study and year & Sensitivity \% & $\begin{array}{c}\text { Specificity } \\
\text { \% }\end{array}$ & $\begin{array}{c}\text { Positive } \\
\text { predictive } \\
\text { value(PPV) }\end{array}$ & $\begin{array}{c}\text { Negative } \\
\text { predictive } \\
\text { value(NPV) }\end{array}$ & Accuracy \\
$\%$ & $\%$ & $\%$ \\
\hline Levitt et al[11] (1978) & 90.0 & 100 & 100 & 96.88 & 97 \\
\hline Bajwa et al [5] (2007) & 97.44 & 100 & 100 & 96.88 & $98.5 \%$ \\
\hline Sagel et al [12] (1977) & 100 & 99.05 & 95.65 & 100 & 99 \\
\hline Present study & 96.55 & 96.77 & 96.55 & 96.77 & 96.6 \\
\hline
\end{tabular}

Calcification and LAP were better seen on CT than USG as shown in Table 6. LAP was seen in 17 cases on CT as against 11 cases on USG. IVC thrombus was found in 2 cases on CT and USG. Our findings are consistent with Weyman et al [18] (1982) who concluded that CT has a definite advantage over other radiographic techniques in its ability to evaluate the composition and precisely locating calcifications within renal masses that results in more accurate evaluation of calcified renal masses.

CT additionally detected perinephric extension in 15 cases, collaterals in 6 cases and fat component in one lesion again signifying the high sensitivity and value of CT over USG. Our study correlates well with study of Levine et al [19] (1980) which concluded that CT was capable of detecting tumor invasion of perinephric fat and adjacent muscles, which cannot usually be shown by ultrasound. While both CT and ultrasound demonstrate venous and retroperitoneal tumor extension, $\mathrm{CT}$ was more reliable.

Our study correlates well with studies of Bajwa et al [5] (2007) and Zagoria et al [20] (1990) who concluded that helical CT is highly sensitive in diagnosing and staging of renal masses. 
Table-10: Role of USG in evaluation of RCC in different studies

\begin{tabular}{|c|c|c|c|c|c|}
\hline Study and year & Sensitivity (\%) & Specificity (0\%) & PPV & NPV & Accuracy \\
$(\%)$ & $(\%)$ & $(\%)$ \\
\hline Warshauer et al [10] (1988) & & 91 & 82 & 73 & \\
\hline $\begin{array}{c}\text { Dachille et al [14] } \\
(2005)\end{array}$ & 80 & 95 & 100 & 84 & 87 \\
\hline $\begin{array}{c}\text { Levitt et al [11] } \\
(1978)\end{array}$ & 60 & 100 & 100 & 93.94 & 85.71 \\
\hline Bajwa et al [5] & & & & \\
\hline (2007) & 94.87 & 87.10 & 86.6 & 90.0 & 88.3 \\
\hline King [13](1972) & 89.66 & 95.4 & 86.67 & 96.5 & 93.9 \\
\hline Present study & 89.66 & & & & \\
\hline
\end{tabular}

Most common appearance of RCC masses was solid 22 (84\%) on USG as against 24 (85\%) on CT as shown in Table 1. 2 masses were cystic on USG and out of these, 1 was cystic on CT. Two lesions showed combined solid and cystic components on both modalities.

Most common echopattern observed was isoechoic (57.6\%) followed by heterogenous on USG as against $96 \%$ on CT in our study as shown in Table 2 and Table 3.

These findings are in agreement with the study of Hatimota et al [6] (2005) where most renal cell carcinomas had a solid appearance. On USG, the most common appearance of RCC was predominantly isoechoic to normal renal parenchyma (78\%) followed by hypoechoic and hyperechoic lesions. On CT, most of the lesions of RCC were heterogeneous in attenuation with inhomogeneous contrast enhancement less than that of normal renal parenchyma.

CT modality was found to be more sensitive in detection of small lesions as one lesion missed on USG was detected on CT, which was measuring less than $3 \mathrm{~cm}(2.6 \mathrm{~cm})$ in size as shown in Table 4. Similarly, the studies by Kostakopoulos et al[15] (1990) and Jamis-Dow et al[16] (1996) showed better sensitivity of CT in detection of small lesions of kidney in comparison to USG but a substantial proportion of small lesions were not visualized with either modality. Study of Bowen et al [1] also concluded that CT and MRI imaging are nearly ideal techniques for the detection, diagnosis, staging, and preoperative evaluation of small renal masses. So, our study is in consistence with these studies.

Cystic lesions belongs to category III and IV were found to be malignant as shown in Table 5 and it also depicted the usefulness of Bosniak classification in cystic renal lesions. Our study correlates well with study of Curry et al [17] (2000) in which all 18 patients of category IV lesions were malignant. 29 (59\%) of 49 pooled category III masses were malignant.

Our study is in agreement with the study of Hatimota et al [6] (2005) who concluded that USG and CT showed many of the key imaging features used to characterize most of the renal neoplasms. However, some lesions remain indeterminate and require percutaneous biopsy to confirm the diagnosis. 


\section{Conclusion}

Renal masses comprise a large variety of space occupying lesions that consisted of nonfunctioning renal tissue. Most of these are neoplastic followed by inflammatory, congenital, cystic or traumatized tissue. CT has higher sensitivity, specificity, accuracy, positive predictive value and negative predictive value for RCC on correlation with USG. Ultrasonography is often the initial modality for imaging of the kidneys, although contrast enhanced $\mathrm{CT}$ is an established imaging modality for the diagnosis of RCC.

CT has a profound impact on diagnostic uroradiology among all modern modalities. It has proven useful for imaging the complete spectrum of renal and ureteral disorders. It allows studies in patients who have dense renal calcification or in whom USG is technically difficult. Helical CT is highly sensitive in diagnosing and staging of renal masses.

CT is capable of detecting tumor invasion of perinephric fat and adjacent muscles, which cannot usually seen by ultrasound. While both CT and ultrasound demonstrate venous and retroperitoneal tumor extension, CT is more reliable.

Funding: Nil, Conflict of interest: None Permission of IRB: Yes

\section{References}

1. Bowen DR and Case JT. Imaging of Small Renal Masses: A Medical Success Story. AJR 2000; 175:945-55.

2. Mittal MK, Sureka B. Solid renal masses in adults. Ijri 2017: 122.173.14.103.

3. Sankineni S, Brown A, Cieciera M, Choyke PL, Turkbey B. Imaging of renal cell carcinoma. Urol Oncol. 2016 Mar;34(3):147-55. doi: 10.1016/j.urolonc.2015.05.020. Epub 2015 Jun 18.

4. Sacco E, Pinto F, Totaro A, D'Addessi A, Racioppi M, Gulino G, Volpe A, Marangi F, D'Agostino D, Bassi P. Imaging of renal cell carcinoma: state of the art and recent advances. Urol Int. 2011;86(2):125-39. doi: 10.1159/000322724. Epub 2010 Dec 11.
5. Bajwa RPS, Sandhu P, Aulakh BS, Sandhu JS, Saggar K, Ahluwalia A. Helical CT Evaluation of Renal Mass Lesions: A Prospective Study. Jiacm 2007;8(3):262-4.

6. Hatimota P, Vashist S, Aggarwal K, Kapoor A, Gupta NP. Spectrum of US and CT findings in renal neoplasms with pathological correlation. Ind J Radiol Imag 2005;15:1:117-25.

7. Lindblad P. Epidemiology of renal cell carcinoma. Scand J Surg. 2004;93(2):88-96.

8. Lipworth L, Tarone RE, McLaughlin JK. The epidemiology of renal cell carcinoma. J Urol. 2006 Dec;176(6 Pt 1):2353-8.

9. Ng CS, Wood CG, Silverman PM, Tannir NM, Tamboli P, Sandler CM. Renal cell carcinoma: diagnosis, staging, and surveillance. AJR Am J Roentgenol. 2008 Oct;191(4):1220-32. doi: 10.2214/AJR.07.3568.

10. Warshauer DM, McCarthy SM, Street L, Bookbinder MJ, Glickman MG, Richter J, Hammers L, Taylor C, Rosenfield AT. Detection of renal masses: sensitivities and specificities of excretory urography/linear tomography, US, and CT. Radiology. 1988 Nov;169(2):363-5.

11. Levitt RG, Geisse GG, Sagel SS, Stanley RJ, Evens RG, Koehler RE, Jost RG. Complementary use of ultrasound and computed tomography in studies of the pancreas and kidney. Radiology. 1978 Jan;126(1):149-52.

12. Sagel SS, Stanley RJ, Levitt RG, Geisse G. Computed tomography of the kidney. Radiology. 1977 Aug;124(2):359-70.

13. King DL. Renal ultrasonography: an aid in the clinical evaluation of renal masses. Radiology. 1972 Dec;105(3):633-40.

14. Dachille G, Erinnio M, Cardo G, Maselli FP, Vestita G, Ludovico GM. Detection rate of ultrasound vs CT scan in clinical staging accuracy of renal tumors pT1NxMx. Arch Ital Urol Androl. 2005 Jun;77(3):149-50.

15. Kostakopoulos A, Antonopoulos P, Drosos C, Stavropoulos N, Picramenos D, Deliveliotis C. Small lesions of the kidney: CT evaluation 
comparison with ultrasound. Acta Urol Belg. 1990;58(3):73-85.

16. Jamis-Dow CA, Choyke PL, Jennings SB, Linehan WM, Thakore KN, Walther MM. Small (< or $=3-\mathrm{cm}$ ) renal masses: detection with CT versus US and pathologic correlation. Radiology. 1996 Mar;198(3):785-8.

17. Curry NS, Cochran ST, Bissada NK. Cystic renal masses: accurate Bosniak classification requires adequate renal CT. AJR Am J Roentgenol. 2000 Aug;175(2):339-42.
18. Weyman PJ, McClennan BL, Lee JK, Stanley RJ. CT of calcified renal masses. AJR Am J Roentgenol. 1982 Jun;138(6):1095-9.

19. Levine E, Maklad NF, Rosenthal SJ, Lee KR, Weigel J. Comparison of computed tomography and ultrasound in abdominal staging of renal cancer. Urology. 1980 Sep;16(3):317-22.

20. Zagoria RJ, Wolfman NT, Karstaedt N, Hinn GC, Dyer RB, Chen YM. CT features of renal cell carcinoma with emphasis on relation to tumor size. Invest Radiol. 1990 Mar;25(3):261-6.

\section{How to cite this article?}

Mohi J.K., Kajal S., Singh J. Imaging evaluation of renal masses. Int J Med Res Rev 2017;5(06):635-643. doi:10.17511/ijmrr. 2017.i06.14. 